\title{
Practice advisory on the treatment of amyotrophic lateral sclerosis with riluzole: \\ Report of the Quality Standards Subcommittee of the American Academy of Neurology
}

\author{
Quality Standards Subcommittee of the American Academy of Neurology
}

Amyotrophic lateral sclerosis (ALS) is a chronic neurodegenerative disorder. No drug treatment was available for ALS patients until the recent approval of riluzole by the US Food and Drug Administration (FDA). Riluzole has a modulating effect on glutamatergic transmission. FDA approval was based on two double-blind, placebo-controlled clinical trials, which demonstrated modest prolongation of survival with out tracheostomy.

Justification. The Quality Standards Subcommittee (QSS) of the American Academy of Neurology is charged with developing evidence-based practice parameters for neurology. As new therapies for specific conditions are introduced, QSS assesses their potential impact and determines whether a practice advisory is needed. In the case of riluzole for ALS, QSS decided that a practice advisory was needed due to (1) the unique action of this drug, (2) the FDA's approval of riluzole as a therapy for ALS, and (3) the limited experience of clinical neurologists with this agent. The cost of this drug is not trivial; its average retail cost is about $\$ 700$ per month.

Process. A MEDLINE search was conducted for all articles published since 1985 with the key word "riluzole." Of 52 identified articles, only two were ALS clinical trials. In addition to the literature review, opinion regarding the use of riluzole was solicited from recognized experts in ALS research and management. Experts were recommended by a QSS member (RM) actively involved with ALS research.
The experts were chosen because of their depth of knowledge in ALS research or their leadership in organizations concerned with ALS diagnosis and management. A draft document was prepared by the QSS chairman. This draft was reviewed by QSS and the expert reviewers simultaneously. Comments from the experts were collected and reviewed by QSS, and a revised document was prepared. The revised version was sent to each expert for additional comment prior to formulating final recommendations.

Scientific evidence. Approval of riluzole for use in treating patients with ALS was based in large part on the results of two controlled clinical trials. The results of the first trial were published in 1994 and the second, larger, multinational study was published in 1996.

The study by Bensimon et al. ${ }^{1}$ was a double-blind, placebo-controlled trial composed of 155 outpatients with definite or probable ALS. The dose of riluzole was $100 \mathrm{mg}$ per day. The patients were randomized with stratification by site of disease onset (bulbar or limb onset). The primary end point was either death or tracheostomy. Patients were excluded if they had symptoms for more than 5 years, a forced vital capacity (FVC) less than $60 \%$ of predicted, another incapacitating or life-threatening disease, liver or renal disease, or if they had undergone tracheostomy or were pregnant. After 12 months, 58\% of patients in the placebo group were still alive, compared with $74 \%$ in the riluzole group $(p=0.014)$. For patients 
with bulbar onset, $35 \%$ of placebo-treated patients were still alive compared with $73 \%$ of riluzoletreated patients; whereas for the limb-onset patients, $64 \%$ of placebo-treated patients were alive compared with $74 \%$ of riluzole patients. At completion of the study, survival was improved by riluzole (37\% of placebo-treated patients versus $49 \%$ of riluzole patients; $p=0.046$ ). The median survival was increased by riluzole in the bulbar-onset patients (239 days with placebo versus $>476$ days with riluzole), but no apparent gain was found in the limbonset patients (523 days with placebo versus 531 days with riluzole).

The second study ${ }^{2}$ was a multinational, multicenter, stratified, double-blind, placebo-controlled, randomized, parallel-group, dose-ranging study in patients with ALS. There were 959 patients enrolled at 31 centers in seven countries. The study started December 17, 1992, ended on February 14, 1995, and treatment duration was 14 to 18 months. The patients were randomized into one of four treatment groups: $50 \mathrm{mg}(\mathrm{N}=237), 100 \mathrm{mg}(\mathrm{N}=236), 200 \mathrm{mg}$ $(\mathrm{N}=244)$, and placebo $(\mathrm{N}=244)$. Outcome measures were similar to those of the first study.

Of the 959 randomized patients, $44.9 \%$ were considered treatment failures due to death, intubation, or tracheostomy (431 of 959), and $21.4 \%$ were prematurely discontinued from treatment (205 of 959). Riluzole and placebo survival curves (Kaplan-Meier) separated at 3 to 6 months and remained separated demonstrating a greater probability for survival with riluzole beginning in the first 6 months of treatment and continuing throughout 15 months of dosing. The stratified log-rank test between 9 and 15 months showed statistical significance in favor of riluzole $100 \mathrm{mg}$. The effect of riluzole in the $200-\mathrm{mg}$ group was not significantly different than in the $100-\mathrm{mg}$ group. Riluzole $50 \mathrm{mg}$ decreased the risk of failure, but statistical significance was not reached compared with placebo. In this study no statistically significant difference between treatment groups was observed for any secondary measure (manual muscle testing, functional scales). Survival analyses for patients taking drug or placebo for 12 months showed that riluzole provided a greater probability of survival. The beneficial effect on survival was similar in bulbar- and limb-onset patients (median survival extended by approximately 60 days).

Recommendations. The symptomatic management of patients with ALS is not changed by the addition of riluzole. Knowledge of the disease natural history and rehabilitation strategies that assist the patient in preventing complications of the inevitable decline in motor power remain the most effective means to prolonging quality survival. Riluzole is not a cure for ALS, but a modest prolongation of survival represents a first step forward in treating ALS patients. No data exist to help predict how any individual patient will benefit from riluzole treatment. The following advisory recommendations are made:

A. ALS patients for whom class I evidence suggests riluzole may prolong survival includes those who have

1. definite or probable ALS by World Federation of Neurology (WFN) criteria ${ }^{3}$ (other causes for progressive muscle atrophy have been excluded)

2. symptoms present for less than 5 years

3. FVC $>60 \%$ predicted

4. no tracheostomy

B. ALS patients for whom no class I evidence supports the use of riluzole, but expert opinion suggests potential benefit includes those who have

1. suspected or possible ALS by WFN criteria

2. symptoms present for more than 5 years

3. FVC $<60 \%$ predicted

4. tracheostomy for prevention of aspiration only (ventilator independent)

C. Expert consensus suggests riluzole is of uncertain benefit in patients with

1. tracheostomy required for ventilation

2. other incurable life-threatening disorders

3. other forms of anterior horn cell disease

No evidence exists to define the duration of the benefit of continued riluzole use. Similarly, there is no evidence of additional benefit if riluzole were continued after tracheostomy is performed for ventilation.

The drug was generally well tolerated. Nausea, diarrhea, and gastrointestinal upset may occur but usually resolve with dose reduction in 1 to 3 weeks, when the initial dose can be reestablished. The liverassociated enzyme alanine transaminase (ALT) must be monitored because slight elevations are common. Threefold elevations occurred in 5 to $10 \%$ of patients, and a fivefold elevation occurred in $3 \%$ of patients. ALT should be obtained monthly for 3 months, every 3 months for the remainder of the first year of treatment, and periodically thereafter. As with any newly approved drug, identification of all possible (or rare) adverse events is beyond the responsibility of the clinical trials, making heightened surveillance for unanticipated adverse events a requirement.

\section{Acknowledgments}

The QSS would like to thank the following individuals for providing expert input into the development of this practice advisory: Michael H. Brooke, MD; Stephen P. Ringel, MD; Theodore L. Munsat, MD; Michael Swash, MD; Hiroshi Mitsumoto, MD; Robert H. Brown, MD; and Lewis P. Rowland, MD. The subcommittee would also like to acknowledge QSS members Michael K. Greenberg, MD, and Robert G. Miller, MD, for their efforts in facilitating the development of this advisory.

QSS members: Michael K. Greenberg, MD, Chair; Milton Alter MD, PhD; John Calverley, MD; Robert G. Miller, MD; Gary Franklin, MD, MPH; Jacqueline French, MD; Douglas J. Lanska, MD; Stephen Ashwal, MD; Shrikant Mishra, MD, MBA; Germaine 
L. Odenheimer, MD; Jay H. Rosenberg, MD; Catherine A. Zahn, MD; James Stevens, MD; and Thomas N. Byrne, Jr., MD.

Note. This statement is provided as an educational service of the American Academy of Neurology. It is based on an assessment of current scientific and clinical information and is not intended to include all possible proper methods of care for a particular neurologic problem or all legitimate criteria for choosing to use a specific procedure. Neither is it intended to exclude any reasonable alternative methods. The American Academy of Neurology recognizes that specific patient-care decisions are the prerogative of the patient and the physician caring for the patient, based on all the circumstances involved.

Organizations invited to review this practice advisory: (*indicates organizations that provided comments): ALS Association; American Academy of Family Physicians; American Academy of Physical Medicine and Rehabilitation*; American Association of Electrodiagnostic Medicine*; American Society of Internal Medicine; Internal Medicine Center to Advance Research and Education; Muscular Dystrophy Association; World Federation of Neurology*; American Academy of Neurology Member Reviewer Network*; American Academy of Neurology Sections that provided review*: Critical Care, Neuro-ophthalmology/otology, Headache and Facial Pain, Neuroimaging, Sleep, History, Neuro-oncology, Behavioral Neurology, Child Neurology, and Pain.

\section{Definitions for classification of evidence:}

\section{Class I:}

Evidence provided by one or more well-designed, randomized, controlled clinical trials, including overviews (meta-analyses) of such trials

\section{Class II:}

Evidence provided by well-designed observational studies with concurrent controls (e.g., case-control and cohort studies)

\section{Class III:}

Evidence provided by expert opinion, case series, case reports, and studies with historical controls

\section{Definitions for strength of recommendations: Standards:}

A principle for patient management that reflects a high degree of clinical certainty (usually this requires class I evidence that directly addresses the clinical question or overwhelming class II evidence when circumstances preclude randomized clinical trials)

\section{Guidelines:}

A recommendation for patient management that reflects moderate clinical certainty (usually this requires class II evidence or a strong consensus of class III evidence)

\section{Practice option:}

A strategy for patient management for which the clinical utility is uncertain (inconclusive or conflicting evidence or opinion)

\section{Practice advisory:}

A practice recommendation for emerging and/or newly approved therapies or technologies based on evidence from at least one class I study. The evidence may demonstrate only a modest statistical effect or limited (partial) clinical response, or significant cost-benefit questions may exist. Substantial (or potential) disagreement among practitioners or between payers and practitioners may exist

\section{References}

Bensimon G, Lacomblez L, Meininger V, et al. A controlled trial of riluzole in amyotrophic lateral sclerosis. N Engl J Med 1994;330:585-591.

2. Lacomblez L, Bensimon G, Nigel Leigh, et al. Dose-ranging study of riluzole in amyotrophic lateral sclerosis. Lancet 1996; 347:1425-1431.

3. Subcommittee on Motor Neuron Diseases/Amyotrophic Lateral Sclerosis of the World Federation of Neurology Research Group on Neuromuscular Diseases and the El Escorial "Clinical Limits of Amyotrophic Lateral Sclerosis" Workshop Contributors. El Escorial World Federation of Neurology criteria for the diagnosis of amyotrophic lateral sclerosis. J Neurol Sci 1994;124(suppl);96-107. 


\section{Neurology}

Practice advisory on the treatment of amyotrophic lateral sclerosis with riluzole: Report of the Quality Standards Subcommittee of the American Academy of Neurology [RETIRED]

Quality Standards Subcommittee of the American Academy of Neurology

Neurology 1997;49;657-659

DOI 10.1212/WNL.49.3.657

This information is current as of September 1,1997

Updated Information \& Services

Citations

Permissions \& Licensing

Reprints including high resolution figures, can be found at: http://n.neurology.org/content/49/3/657.full

This article has been cited by 6 HighWire-hosted articles: http://n.neurology.org/content/49/3/657.full\#\#otherarticles

Information about reproducing this article in parts (figures,tables) or in its entirety can be found online at:

http://www.neurology.org/about/about_the_journal\#permissions

Information about ordering reprints can be found online:

http://n.neurology.org/subscribers/advertise

Neurology ${ }^{\circledR}$ is the official journal of the American Academy of Neurology. Published continuously since 1951, it is now a weekly with 48 issues per year. Copyright . All rights reserved. Print ISSN: 0028-3878. Online ISSN: 1526-632X.

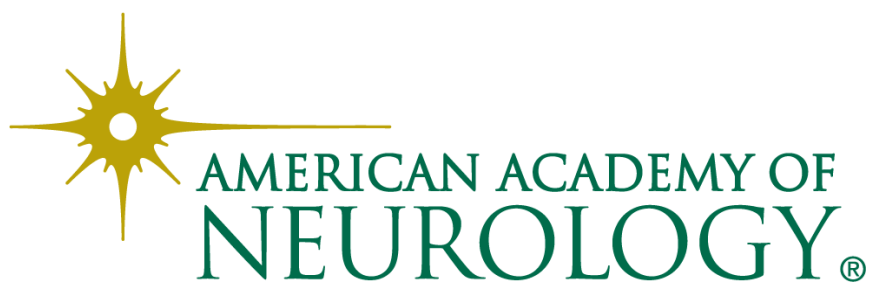

